\title{
Estado Nutricional Em Portadores De Síndrome De Down Com Cardiopatia Congênita: Comparação De Curvas De Crescimento
}

\author{
Foscarini, A.C.; Dornelles, I.K.; Sica, A.S.; Cesa, C.C.; Pellanda, L.C.; \\ Apresentador: Ana Carolina Foscarini
}

\section{Resumo}

Introdução: Em crianças portadoras de Síndorme de Down (SD), a presença de cardiopatia congênita (CC) ocorre em $40 \%$ a $50 \%$ dos casos. Ademais segundo a Organização Mundial de Saúde (OMS) - a obesidade está presente em cerca de $30 \%$ delas. Contudo, pouco se sabe acerca da prevalência de obesidade em jovens com SD e CC associadas. Objetivamos, portanto, avaliar hábitos alimentares, estado nutricional e frequência alimentar em crianças e adolescentes portadores de SD com CC, comparar as classificações de índice de massa corporal (IMC) de acordo com curvas da OMS e curvas desenvolvidas para indivíduos com SD. Métodos: Estudo transversal com indivíduos portadores de SD atendidos em um centro de referência para cardiologia, portadores de CC, com idade de 2 a 18 anos. Foram aferidos peso, altura, IMC, valor energético total (VET) e frequência alimentar, por meio de questionário aplicado aos pais/cuidadores e de exame físico. $\mathrm{O}$ estado nutricional foi analisado mediante IMC para gênero e idade, utilizando-se as curvas para avaliação de portadores de SD preconizadas pela Myrelid et al. e pelas propostas pela OMS. As prevalências foram descritas sob a forma de percentual com respectivos intervalos de confiança de $95 \%$ e foi considerado significativo um $\mathrm{p}<0,05$. Resultados: Foram avaliados 68 indivíduos portadores de SD com CC. O defeito septo atrioventricular (DSAV) foi a cardiopatia mais frequente $(52,9 \%)$. O consumo adequado de carboidratos, proteínas e lipídeos foram atingidos por $66,2 \%$, $94,1 \%$ e $41,2 \%$ respectivamente. Houve diferença de classificação do IMC entre as curvas propostas para portadores de SD e pela OMS. Houve associação entre consumo de vitamina $\mathrm{E}$ e ácidos graxos poli-insaturados. Conclusão: Os resultados mostraram que indivíduos com SD são, em sua maioria, considerados eutróficos para idade, quando avaliados pelas curvas específicas para SD. Porém, a prevalência de sobrepeso e obesidade foi abaixo do esperado neste estudo quando comparamos as curvas de IMC para idade, preconizadas pela OMS. As avaliações nas curvas específicas para SD seriam o recomendado na prática dos profissionais da área da saúde, para assim evitar diagnósticos precipitados de sobrepeso e/ou obesidade nesta população.

\section{Referência:}

Foscarini, A.C.; Dornelles, I.K.; Sica, A.S.; Cesa, C.C.; Pellanda, L.C.;. Estado Nutricional Em Portadores De Síndrome De Down Com Cardiopatia Congênita: Comparação De Curvas De Crescimento. In: II Congresso Brasileiro de Medicina Hospitalar - II CBMH [= Blucher Medical Proceedings, vol.1, num.5] São Paulo: Editora Blucher, 2014. p.17

DOI 10.5151/medpro-II-cbmh-008 